\title{
Article \\ A Combination of Aqueous Extraction and Ultrafiltration for the Purification of Phycocyanin from Arthrospira maxima
}

\author{
Dante Matteo Nisticò ${ }^{1}$, Amalia Piro ${ }^{1} \mathbb{D}$, Daniela Oliva ${ }^{1}$, Vincenzo Osso ${ }^{1}$, Silvia Mazzuca ${ }^{1, *}$, Francesco \\ Antonio Fagà ${ }^{2}$, Rosanna Morelli ${ }^{3}$, Carmela Conidi ${ }^{3}$, Alberto Figoli ${ }^{3}\left[\right.$ and Alfredo Cassano ${ }^{3, *}$ (D) \\ 1 Laboratorio di Biologia e Proteomica Vegetale, Dipartimento di Chimica e Tecnologie Chimiche, \\ Università della Calabria, Via P. Bucci 12/C, 87036 Rende, Italy; dante.nistico@unical.it (D.M.N.); \\ amalia.piro@unical.it (A.P.); daniela.oliva@unical.it (D.O.); vincent0593@hotmail.it (V.O.) \\ 2 BIORISI S.r.l.-Oil Fox Europe, Via G. Pinna 78, 88046 Lamezia Terme, Italy; direzione@biorisi.it \\ 3 Istituto per la Tecnologia delle Membrane (ITM-CNR), Università della Calabria, Via P. Bucci 17/C, \\ 87036 Rende, Italy; r.morelli@itm.cnr.it (R.M.); c.conidi@itm.cnr.it (C.C.); a.figoli@itm.cnr.it (A.F.) \\ * Correspondence: silvia.mazzuca@unical.it (S.M.); a.cassano@itm.cnr.it (A.C.)
}

\section{check for}

updates

Citation: Nisticò, D.M.; Piro, A.;

Oliva, D.; Osso, V.; Mazzuca, S.; Fagà,

F.A.; Morelli, R.; Conidi, C.; Figoli, A.;

Cassano, A. A Combination of

Aqueous Extraction and

Ultrafiltration for the Purification of

Phycocyanin from Arthrospira maxima.

Microorganisms 2022, 10, 308.

https://doi.org/10.3390/

microorganisms 10020308

Academic Editor: Assaf Sukenik

Received: 15 December 2021

Accepted: 26 January 2022

Published: 28 January 2022

Publisher's Note: MDPI stays neutral with regard to jurisdictional claims in published maps and institutional affiliations.

Copyright: (C) 2022 by the authors. Licensee MDPI, Basel, Switzerland. This article is an open access article distributed under the terms and conditions of the Creative Commons Attribution (CC BY) license (https:// creativecommons.org/licenses/by/ $4.0 /)$.

\begin{abstract}
The purification of phycocyanin (PC) from Spirulina generally involves a combination of different techniques. Here, we report the results on PC yields from a combined aqueous extractionultrafiltration (UF) process of a strain of Arthrospira maxima cultivated in a farm devoted to producing PC with food-grade purity. Samples optimized from different biomass/solvent ratios were purified by using a polyethersulphone (PES) membrane with a molecular weight cut-off (MWCO) of $20 \mathrm{kDa}$. The UF system was operated at $2.0 \pm 0.1$ bar and at $24 \pm 2{ }^{\circ} \mathrm{C}$ up to a volume concentration factor (VCF) of 5. A diafiltration (DF) process was conducted after UF in order to increase the PC recovery in the retentate. Samples were collected during both UF and DF processes in order to evaluate membrane productivity and PC purity. The average permeate fluxes of about $14.4 \mathrm{~L} / \mathrm{m}^{2} \mathrm{~h}$ were measured in the selected operating conditions and more than $96 \%$ of PC was rejected by the UF membrane independently ofthe extraction yields and times. The concentration of PC in the final retentate was $1.17 \mathrm{mg} / \mathrm{mL}$; this confirmed the observed rejection and the final VCF of the process (about 5-fold when compared to the concentration of PC in the crude extract). In addition, the combination of UF and diafiltration allowed the removal of about $91.7 \%$ of the DNA from the crude extract, thereby improving the purity of the phycocyanin in the retentate fraction.
\end{abstract}

Keywords: Spirulina; phycocyanin; extraction; ultrafiltration; diafiltration

\section{Introduction}

Photosynthetic organisms, such as microalgae and cyanobacteriarepresent promising renewable sources of healthy food ingredients and functional food products due to their high contents of bioactive compounds, such as essential amino acids, antioxidant molecules, minerals and fibers. Compared to other natural sources of bioactive ingredients, these organisms have many advantages, including a wide biodiversity, the possibility to grow under conditions of low water utilization and the plasticity of their metabolism, which can be induced to produce specific molecules [1,2].

The production of microalgae-based protein products, for example, involve microalgae cultivation followed by harvesting, drying, cell disruption, protein extraction, hydrolysis and separation [3]. Among cyanobacteria, Arthrospira platensis (traditionally known as Spirulina), a blue-green coil shaped species, has received increased attention in receent years due to its high content of proteins, vitamins, minerals and many essential amino-acids and fatty acids [4]. It is an important source of phycocyanin (PC) and allophycocyanin (APC) water soluble proteins belonging to the phycobiliprotein family [5]. PC is a natural blue colorant, with an estimated molecular weight of 100-200 kDa; thanks to its therapeutic 
properties as an antioxidant, anti-inflammatory molecule, as well as its anti-cancer activities [6-9], the PC has great potential for industrial and commercial development. Its market value is estimated to be around 10-50 million US\$ per annum [10].

The purification of PC from Spirulina and other microalgae has been investigated and optimized by several authors [11-16]. Purification generally involves different techniques that include extraction, centrifugation and separation by chromatography or ion exchange and dialysis. These procedures are time consuming and directly increase facilities and equipment-related expenses, thereby leading to an increase in production costs. In this context, membrane-based processes, such as microfiltration (MF) and ultrafiltration (UF), offer a useful approach as fractionation, purification and concentration steps asalternatives to expensive sequential purification techniques such as ammonium sulphate precipitation and gel filtration chromatography. These processes, thanks to their mild operating conditions, prevent possible thermal denaturation and deactivation of the PC molecules. Additional advantages over conventional technologies includean easy scale-up combined with high selectivity, modularity, low energy consumption, no phase change and no use of chemical additives $[17,18]$.

UF membranes with a molecular weight cut-off (MWCO) of $50 \mathrm{kDa}$ were used by Herrera et al. [19] to concentrate a spirulina extract up to a VCF of 1.9. A food grade phycocyanin powder with a purity ratio of 0.74 was obtained after adsorption on activated charcoal and spray drying. Jaouen et al. [20] investigated the use of MF and UF tubular inorganic membranes for the clarification of raw extracts after sonication of a spirulina culture, while UF, nanofiltration (NF) and reverse osmosis (RO) organic membranes were used for the concentration of the clarified extract. NF membranes exhibited the best performance in the concentration of the clarified extract: in selected conditions of operating pressure and tangential velocity ( 30 bar and $1.5 \mathrm{~m} / \mathrm{s}$, respectively), the recovery of PC and permeation flux resulted in $100 \%$ and $85 \mathrm{~L} / \mathrm{m}^{2} \mathrm{~h}$, respectively.

A combination of an aqueous two-phase system, UF and precipitation was developed by Rito-Palomares et al. [15] in order to reduce the number of unit operations and increased the yield of the protein. In this approach, the use of a $30 \mathrm{kDa}$ UF membrane followed by precipitation with ammonium sulfate led to a protein purity of $3.8 \pm 0.1 \%$ and an overall product yield of $29.5 \%(w / w)$.

Figueira et al. [21] obtained a C-PC extract with purity of 0.95 suitable for use as a food dye (purity between 0.75 and 1.5) by using a combination of UF and 6 diafiltration cycles. In this approach, a $50 \mathrm{kDa}$ polyethersulfone UF membrane in flat-sheet configuration was used.

Recently, Brião et al. [22] simplified the purification step by using the phosphate buffer extraction followed by UF and one-step of diafiltration (DF) membranes; throughthis procedure, a food-grade PC from A. platensis has been produced. Similarly, UF in diafiltration mode was assessed by Balti et al. [23] for protein fractionation of $A$. platensis in order to produce different protein extracts more or less purified, notably in salt and chlorophyll.

This study aimed at developing a sustainable process for the recovery, fractionation and purification of PC from a strain of A. maxima extracts. It was based on a 'green' aqueous extraction of PC from the Arthrosphira biomass followed by a purification/fractionation step of the centrifuged extract through the use of a $20 \mathrm{kDa}$ UF membrane aimed at removing mainly non-protein molecules, such as DNA, co-extracted with phycobiliproteins. To enhance the PC purification, UF was combined with a diafiltration (DF) step based on the addition of purified water to the UF retentate.

The effect of the biomass-water ratio on the PC concentration was investigated. Membrane productivity, cleaning efficiency and membrane retention towards PC and DNA were also assessed. 


\section{Materials and Methods}

\subsection{Chemicals}

Bradford reagent, water CHROMASOLV ${ }^{\circledR}$ Plus for HPLC, bromophenol blue ACS reagent, ammonium bicarbonate BioUltra ( $\geq 99.5 \%)$ and acetonitrile anhydrous $(99.8 \%)$ wereall acquired from Sigma-Aldrich (Milan, Italy). A 40\% acrylamide/bis solution, ammonium persulfate, sodium dodecyl sulfate (SDS), trimethamine and glycine were purchased from Bio-Rad Laboratories (Hercules, CA, USA). Boric acid and ethylenediaminetetraacetic acid (EDTA) were acquired from Carlo Erba (Milan, Italy). Glycerol 99.0-101.0\% was purchased from Honeywell Research Chemicals (Seelze, Germany). Coomassie R-250 solution was purchased fromAmersham Pharmacia Biotech (Uppsala, Sweden). Agarose CSL-AG5 for gel electrophoresis was purchased from Cleaver Scientific (Rugby, UK). Gel red nucleic acid gel stain 10,000 $\times$ in water was purchased from Biotium (Fremont, CA, USA). Tetramethylethylendiamine (TEMED) was purchased from Chem-Lab (Zedelgem, Belgium). GeneRuler DNA Ladders $10 \mathrm{Kpb}$ was purchased from Thermo Fisher Scientific Inc. (Swindon, UK). All other reagents were of analytical grade.

\subsection{Biological Materials}

Dried biomass samples of the Arthrospira maxima strain cultivated according to the Oil Fox ${ }^{\circledR}$ technology and registered trademark Spirulina-fox ${ }^{\circledR}$ and covered by an international patent [24] were used.

\subsection{Aqueous Extraction of Phycocyanin (PC) from A. maxima Biomass}

The PC extraction from $A$. maxima samples was carried out at different biomasssolvent ratios in order to investigate the amount of solvent needed to maximize the yield of extraction. Ultrapure distilled water was added to dried A. maxima biomass to obtain suspensions of $200 \mathrm{~mL}$ at concentrations of $0.005,0.01,0.015$ and $0.02 \mathrm{~g} / \mathrm{mL}$, respectively. All suspensions were stirred on a magnetic plate at $500 \mathrm{rpm}$ for $24 \mathrm{~h}$ at RT. Three independent extractions were carried out and results of the PC concentration were expressed as mean value $\pm \mathrm{SD}$

\subsection{Feed Solution}

After incubation time, the crude extract of $A$. maxima was centrifuged for $15 \mathrm{~min}$ at $6000 \mathrm{rpm}$, the supernatant removed and then frozen at $-20{ }^{\circ} \mathrm{C}$. The supernatant was used as a feed solution in the ultrafiltration experiments.

\subsection{Ultrafiltration (UF): Experimental Set-Up and Procedure}

Dead-end UF experiments were performed using the Sterlitech ${ }^{\mathrm{TM}} \mathrm{HP} 4750$ highpressure stirred cell (Sterlitech, Kent, WA, USA) with a filter area of $13.85 \mathrm{~cm}^{2}$ and a processing capacity of $300 \mathrm{~mL}$. The cell filtration system was equipped with a flat-sheet polyethersulphone (PES) membrane (Nadir ${ }^{\circledR}$ UP020 P, from Microdyn-Nadir GmbH, Wiesbaden, Germany) with a thickness of 210-250 $\mu \mathrm{m}$ and a nominal MWCO of $20 \mathrm{kDa}$. Filtration experiments were carried out according to a batch concentration configuration at a transmembrane pressure (TMP) of 2 bar and an operating temperature of $24 \pm 2{ }^{\circ} \mathrm{C}$. Stirring inside the cell was accomplished by using a magnetic stirrer. An initial volume of crude extract (UF feed) of $100 \mathrm{~mL}$ was used and the permeate was collected separately up to a final volume of $80 \mathrm{~mL}$ corresponding to a volume concentration factor (VCF) of 5 .

VCF is dimensionless and defined as:

$$
\mathrm{VCF}=\frac{V_{f}}{V_{r}}
$$

where $V_{f}$ and $V_{r}$ are the feed and retentate volumes, respectively.

Diafiltration experiments were performed by adding distilled water to the UF retentate at the same flowrate of the permeate so as to keep the retentate volume constant $(15 \mathrm{~mL})$ 
during the process. Six diafiltration volumes (addition of $90 \mathrm{~mL}$ of distilled water) were added before stopping filtration.

The diafiltration volume (ratio of the solvent volume added per volume of feed solution) was determined as follows [25]:

$$
D V=\frac{V_{p}}{V_{0}}=\frac{V_{w}}{V_{0}}
$$

where $V_{p}$ and $V_{0}$ are the volumes of permeate and feed solution, respectively, and $V_{w}$ is the volume of water added during the diafiltration process.

The diafiltration was operated at the same parameters of temperature, stirring conditions and transmembrane pressure asthe UF.

The schematic flowchart of the combined extraction-filtration process investigated in this study is depicted in Figure 1.

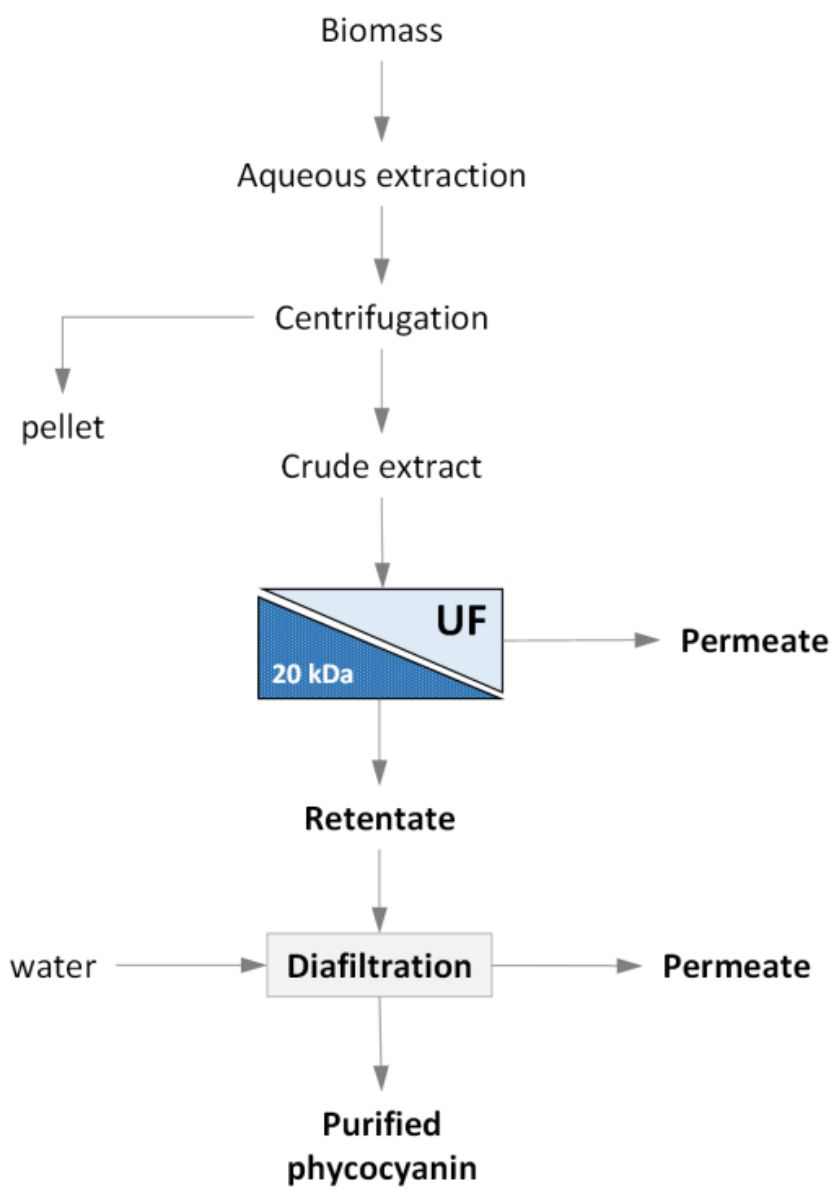

Figure 1. Schematic flowchart of the combined extraction/UF process investigated.

\subsection{Data Processing}

The permeate flux $\left(J_{p}\right)$, expressed in $\mathrm{L} / \mathrm{m}^{2} \mathrm{~h}$, was determined by measuring the permeate volume collected in a given time according to Equation (3):

$$
J_{p}=\frac{V_{p}}{t A}
$$

where $V_{p}(\mathrm{~L})$ is the permeate volume, $t(\mathrm{~h})$ is the permeation time and $A\left(\mathrm{~m}^{2}\right)$ is the membrane area.

The hydraulic permeability of the UF membrane was determined by measuring the water permeate flux at different TMP values (at an operating temperature of $25^{\circ} \mathrm{C}$ ). The 
fouling index was determined by measuring the hydraulic permeability before and after filtration experiments, according to the following equation:

$$
F I=\left(\frac{W_{p 1}}{W_{p 0}}\right) \cdot 100
$$

where $W_{p 0}$ and $W_{p 1}$ are the pure water permeability before and after UF experiments, respectively.

After the experiments with the crude extract, the UF membrane was cleaned in two steps. The first cleaning step was performed with distilled water for $30 \mathrm{~min}$ at a temperature of $40{ }^{\circ} \mathrm{C}$ in order to remove the reversible polarized layer. The hydraulic permeability measured afterwards was $W_{p 2}$.

In the second step, the membrane was submitted to an enzymatic cleaning with a solution of Ultrasil P3 (Henkel-Ecolab, Dusseldorf, Germany) at $0.5 \% w / w$ for $30 \mathrm{~min}$ at $40{ }^{\circ} \mathrm{C}$. At the end of the cleaning procedure, the membrane was rinsed with distilled water for $10 \mathrm{~min}$ and the hydraulic permeability, indicated as $W_{p 3}$, was measured.

The cleaning efficiency $(C E)$ was evaluated by using the flux recovery method according to the following equation:

$$
C E=\left(\frac{W_{p 3}}{W_{p 0}}\right) \cdot 100
$$

where $W_{p 3}$ is the water permeability measured after the enzymatic cleaning.

The rejection rate $(R)$ of PC was calculated as described in Equation (6):

$$
R=\left(1-\frac{C_{p}}{C_{f}}\right) \cdot 100
$$

where $C_{p}$ and $C_{f}$ refer to the concentration of PC within the permeate and feed, respectively.

\subsection{Analytical Assays}

\subsubsection{Phycocyanin (PC) Concentration}

The PC concentration was measured by using a UV-VIS spectrophotometer (Shimadzu UV-160A, Kyoto, Japan) at wavelengths of $615 \mathrm{~nm}$ and $652 \mathrm{~nm}$. The total amount of PC was calculated by using the following equation [26,27]:

$$
P C=\frac{A_{615}-0.474\left(\mathrm{~A}_{652}\right)}{5.34}
$$

where $\mathrm{PC}$ is the phycocyanin concentration $(\mathrm{mg} / \mathrm{mL}), \mathrm{A}_{615}$ is the optical density of the sample at $615 \mathrm{~nm}$ and $A_{652}$ is the optical density of the sample at $652 \mathrm{~nm}$.

The PC purity was monitored spectrophotometrically by the $A_{615} / A_{280}$ ratio [28] according to the Equation (8):

$$
\mathrm{PP}=\frac{\mathrm{A}_{615}}{\mathrm{~A}_{280}}
$$

where $A_{280}$ is the optical density of the sample at $280 \mathrm{~nm}$.

The purification factor $(P F)$ was calculated from the ratio of PC concentration in purified $\left(P C_{p}\right)$ and crude extract $\left(P C_{c}\right)$ by Equation (9) [29]:

$$
P F=\frac{P C_{p}}{P C_{c}}
$$

\subsubsection{Protein Analysis by SDS-PAGE of the Feed, Retentate and Permeate after UF}

The protein concentration was measured by the Bradford method [30] and the protein sample was separated by the acrylammide gel electrophoresis under denaturant conditions (SDS-PAGE) [31]. The protein extract, solubilized in a loading buffer, was activated for $4 \mathrm{~min}$ at $100{ }^{\circ} \mathrm{C}$. $20 \mu \mathrm{L}$ for each sample were loaded onto a $12 \%$ polyacrylamide gel. The electrophoretic run was performed by placing the gel in the electrophoretic chamber filled 
with a buffer solution (Buffer Tris Glycine) and setting the amperage and voltage (60 $\mathrm{mA}$ in the stacking gel and $120 \mathrm{~mA}$ in the running gel at a power of $200 \mathrm{~V}$ ). Once the run was over, the gels were placed in a Coomassie R-250 solution overnight and then destained by washing in water, ammonium bicarbonate and acetonitrile solution. The gels were scanned using the "GS800" (Biorad, Hercules, CA, USA) densitometer and analyzed with the "QuantityOne" software (Biorad, Hercules, CA, USA) to identify the polypeptide bands.

\subsubsection{DNA Detection}

To evaluate the nucleic acid occurrence in the three fractions after ultrafiltration, the quantity of DNA molecules has been assessed by the NanoDrop ${ }^{\mathrm{TM}}$ One/One ${ }^{\mathrm{C}}$ Microvolume UV-Vis Spectrophotometer (Thermo Fisher Scientific Inc., London, UK); absorbances at $260 \mathrm{~nm}$ and $280 \mathrm{~nm}$ were measured and concentrations were calculated as:

$$
\text { DNA concentration }(\mathrm{ng} / \mu \mathrm{L})=\mathrm{A}_{260 \mathrm{~nm}} \cdot \frac{50 \mathrm{ng} / \mu \mathrm{L}}{1 \mathrm{a} . \mathrm{u} \text {. }}
$$

The quality of the DNA has been evaluated by the direct measurements of the ratios $\mathrm{A}_{260} / \mathrm{A}_{280}$.

For the electrophoresis analysis, equal volumes of feed, permeate and retentate from the same UF assay were solubilized in an equal volume of loading buffer under stirring overnight at RT. Samples were separated in a $0.8 \%$ agarose gel using $0.5 \mathrm{X}$ TBE as the running buffer; bromophenol blue was added to the samples as a tracking dye. The $10 \mathrm{kbp}$ DNA ladder was used (Thermo Fisher Scientific Inc.). After $30 \mathrm{~min}$ of running at $70 \mathrm{~mA}$, $120 \mathrm{~V}$, the gel image was digitalized using a UV Transilluminator (Consort bvba, Turnhout, Belgium) equipped with a photocamera.

All analytical measurements were performed in triplicate. Results were expressed as mean value \pm SD.

\section{Results}

\subsection{Aqueous Extraction of PC}

The variable biomass-solvent ratio strongly influences the PC concentration in the aqueous extract [32]. As illustrated in Figure 2, the maximum yield of PC $(0.232 \pm 0.0042 \mathrm{mg} / \mathrm{mL})$ in the aqueous extract was obtained by using the largest biomasssolvent ratio $(0.02 \mathrm{~g} / \mathrm{mL})$. Therefore, UF experiments were performed by using an aqueous extract sample obtained with a biomass-solvent ratio of $0.02 \mathrm{~g} / \mathrm{mL}$.

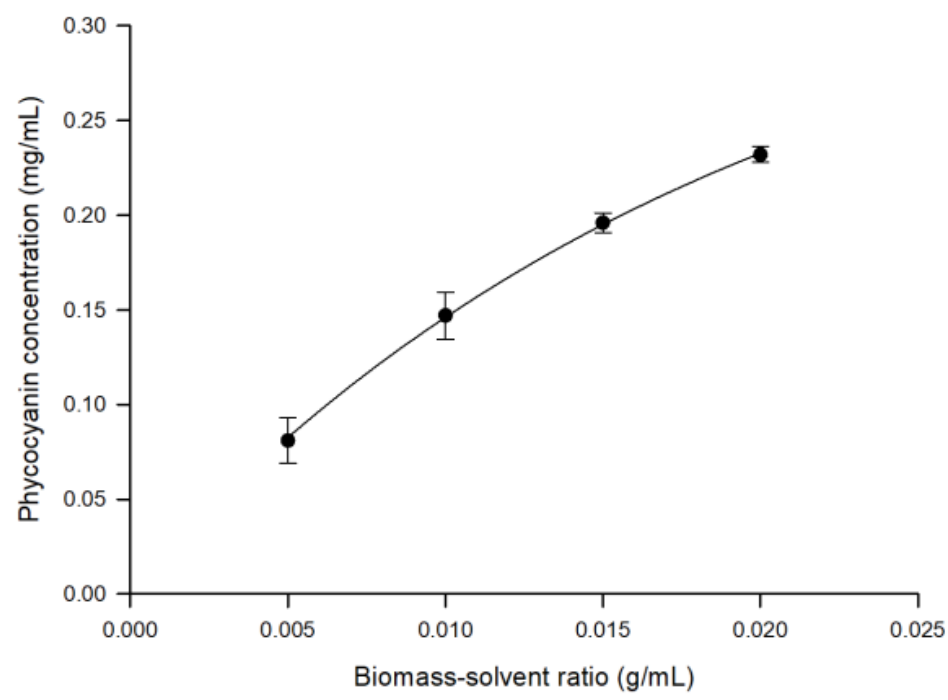

Figure 2. Extraction of phycocyanin from A. maxima. Effect of biomass-solvent ratio on phycocyanin concentration.

In Figure 3, the SDS-PAGE pattern of the supernatant from the crude extract at different biomass-solvent ratiosis reported. As it is observed, only a prominent polypeptide band at 
approx. $19 \mathrm{kDa}$ was resolved in all aqueous extracts. The abundance of this band increased accordingly with the concentration of the extracts. Very weak bands at $50 \mathrm{kDa}, 35 \mathrm{kDa}$ and $10 \mathrm{kDa}$ were also detected.The majority of A. maxima proteins, mainly the hydrophobic ones, remained in the biomass pellet, along with all the other water insoluble molecules (see the Supplementary Figure S1).

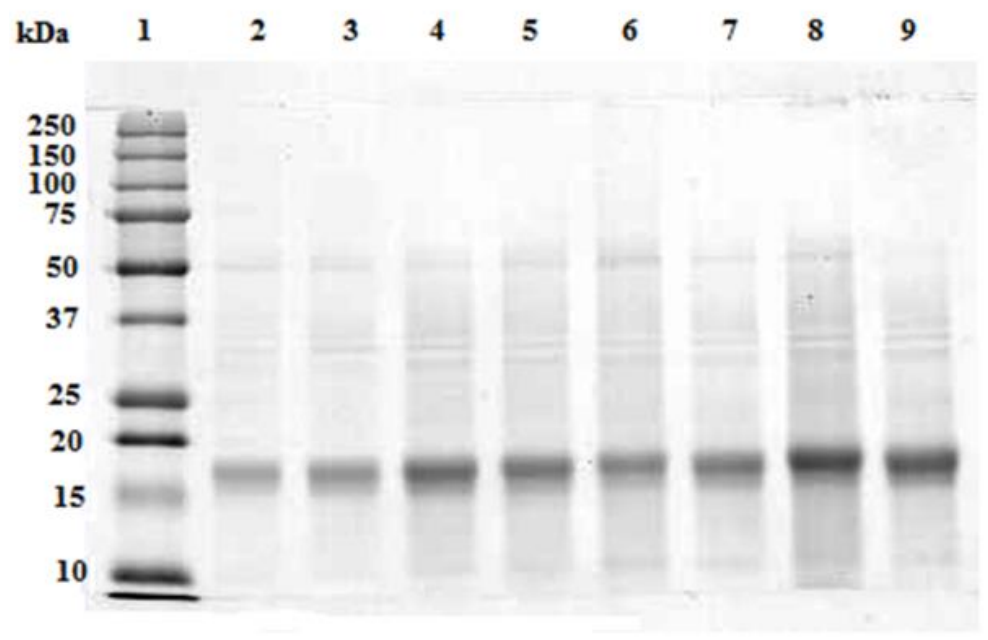

Figure 3. SDS-PAGE of the centrifuged extracts from $0.005 \mathrm{~g} / \mathrm{mL}$ (lanes 2 and 3), $0.010 \mathrm{~g} / \mathrm{mL}$ (lanes 4 and 5), $0.015 \mathrm{~g} / \mathrm{mL}$ (lanes 6 and 7) and $0.020 \mathrm{~g} / \mathrm{mL}$ (lanes 8 and 9) biomass-solvent ratio. $20 \mu \mathrm{L}$ of each extract were loaded on the gel. Precision Plus ProteinTM Standards (Biorad, Hercules, CA, USA) were loaded on lane 1.

\subsection{Ultrafiltration/Diafiltration}

The feed solution was ultrafiltered with the selected membrane under operating conditions of pressure and temperature of 2 bar and $24 \pm 2{ }^{\circ} \mathrm{C}$, respectively. The initial permeate flux of about $19.2 \mathrm{~L} / \mathrm{m}^{2} \mathrm{~h}$ decreased sharply to $26.5 \%$ in the first steps of the process to reach a steady-state value of about $11.5 \mathrm{~L} / \mathrm{m}^{2} \mathrm{~h}$ at a VCF of 3.1 ; then, the permeate flux continued to decrease, reaching $9.5 \mathrm{~L} / \mathrm{m}^{2} \mathrm{~h}$ when the final VCF of 5 was reached (Figure 4 ).

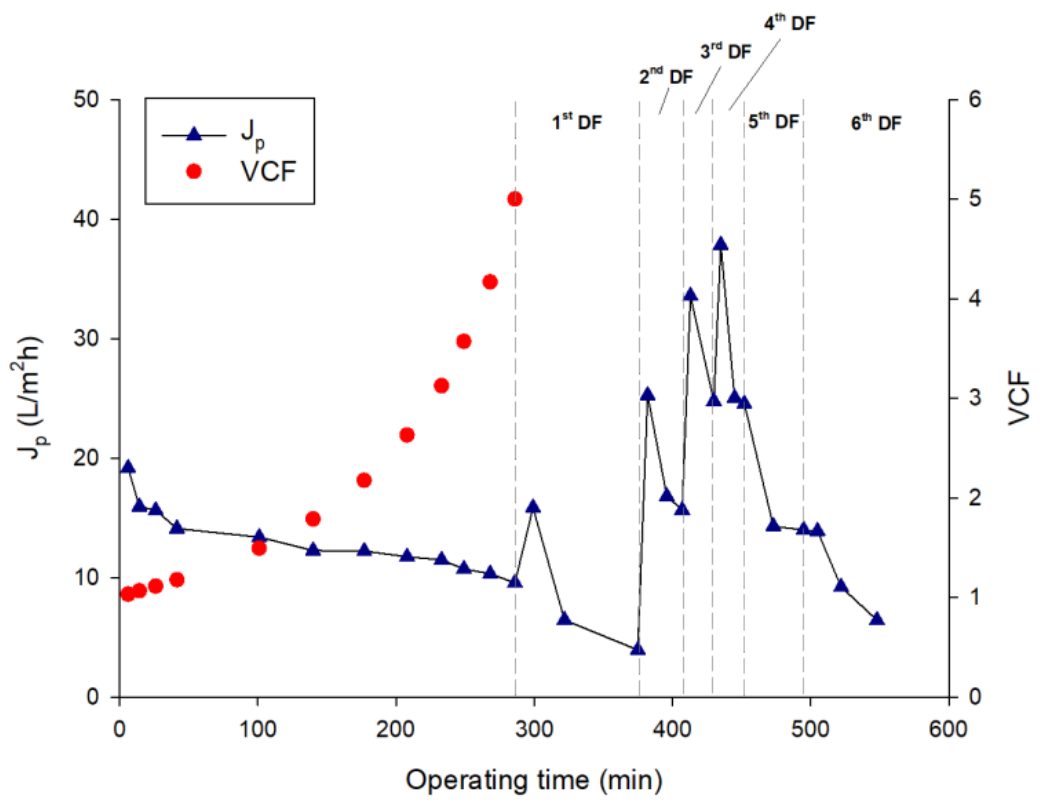

Figure 4. Ultrafiltration of A. maxima extract followed by six steps of diafiltration. Time course of permeate flux and volume concentration factor (VCF). 
The addition of water in the DF steps produced a dilution of the retentate stream and an increase of the permeate flux at the beginning of each cycle of DF (with the exception of the last two DF steps) (Figure 4), followed by flux decay due to concentration polarization phenomena [22]. Figures 5 and 6 illustrate the samples collected during the UF and DF steps, respectively.

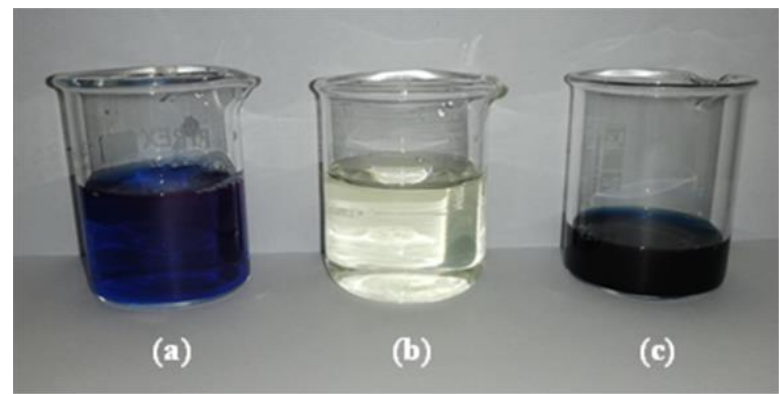

Figure 5. UF samples. (a) Aqueous crude extract (supernatant of centrifugation); (b) UF permeate; (c) UF retentate (at VCF 5).

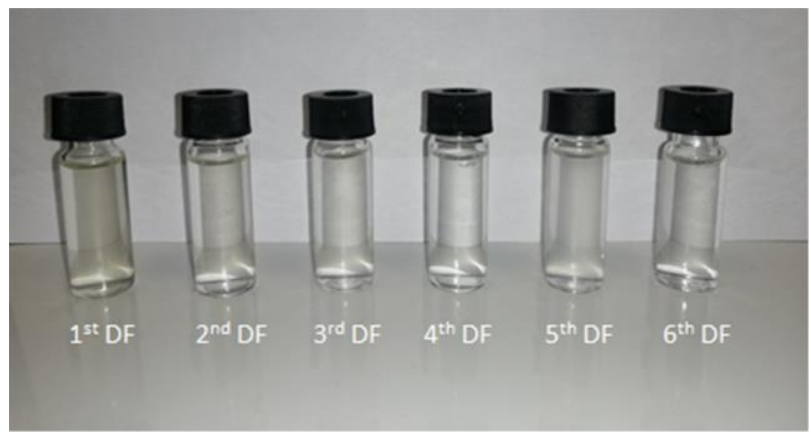

Figure 6. Permeate samples recovered in the course of diafiltration.

Figure 7 shows the pure water flux of the UF membrane before and after the treatment of the crude extract and after cleaning treatments. The initial water permeability of the membrane, of about $140.3 \mathrm{~L} / \mathrm{m}^{2} \mathrm{hbar}$, dropped to $67.0 \mathrm{~L} / \mathrm{m}^{2} \mathrm{hbar}$ after the treatment of the crude extract. Therefore, the fouling index was estimated to be $52.3 \%$. The cleaning with distilled water and enzymatic detergent at $40{ }^{\circ} \mathrm{C}$ allowed an increase in the membrane water permeability at $74.9 \mathrm{~L} / \mathrm{m}^{2} \mathrm{hbar}$ and $114.2 \mathrm{~L} / \mathrm{m}^{2} \mathrm{hbar}$, respectively. Thus, the cleaning efficiency result was about $81 \%$.

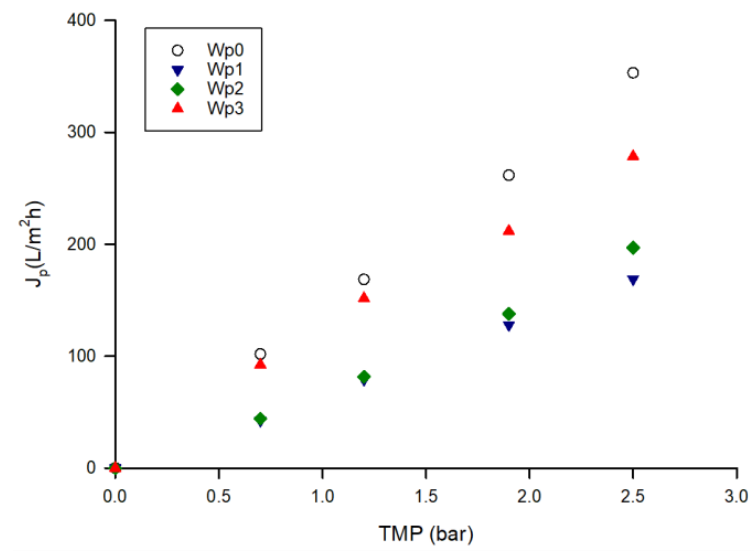

Figure 7. Water permeability of UF membrane before the treatment of aqueous extract and after cleaning procedures $\left(W_{p 0}\right.$, initial water permeability; $W_{p 1}$, water permeability after treatment of aqueous extract; $W_{p 2}$, water permeability after cleaning with water; $W_{p 3}$, water permeability after enzymatic cleaning). 


\subsection{Analyses of Phycocyanin}

In Figure 8, the electrophoresis of the fractions obtained after the UF treatment of the $0.020 \mathrm{~g} / \mathrm{mL}$ feed solution is shown. Only one polypeptide band of aprox. $19 \mathrm{kDa}$ was resolved in feed and retentates. This band appeared more concentrated in the retentate withrespect to the starting concentration of the feed fraction. No polypeptide band has been resolved in the permeate fraction.

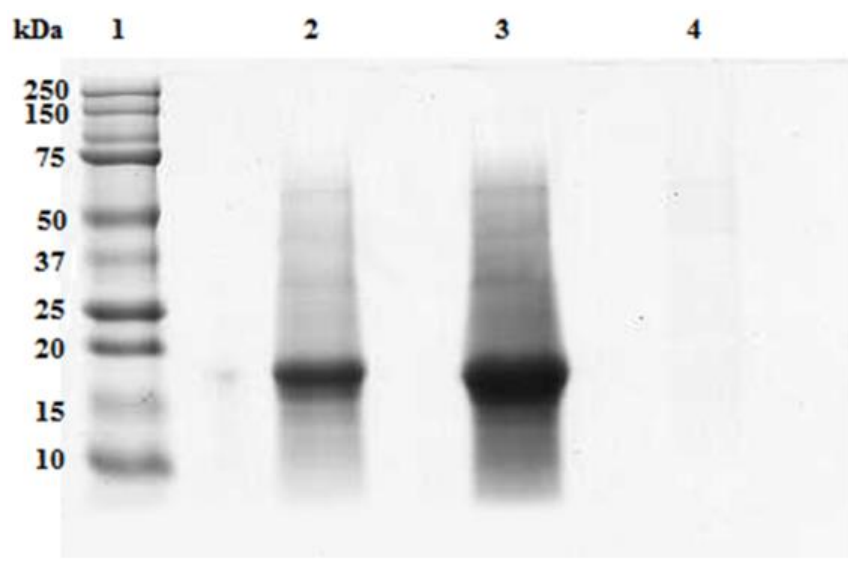

Figure 8. SDS-PAGE of the UF fractions from the aqueous extract of A. maxima at a concentration of $0.02 \mathrm{~g} / \mathrm{mL}$.An intense polypeptide band of approximately $19 \mathrm{kDa}$ was resolved in the feed (lane 2) which became more intense in the retentate (lane 3) but was not detectable in the permeated fraction (lane 4). $20 \mu \mathrm{L}$ of each fraction were loaded on the gel. Precision Plus ProteinTM Standards (Biorad, Hercules, CA, USA) wereloaded on lane 1.

In Figure 9, the absorbance spectra of the UF fractions in the range of $480-750 \mathrm{~nm}$ are reported. Higher absorbance was observed in the retentate fraction with respect to feed and permeate samples. The concentration of PC and related purity in the feed in the UF fractions and in the final retentate after diafiltration are reported in Table 1.

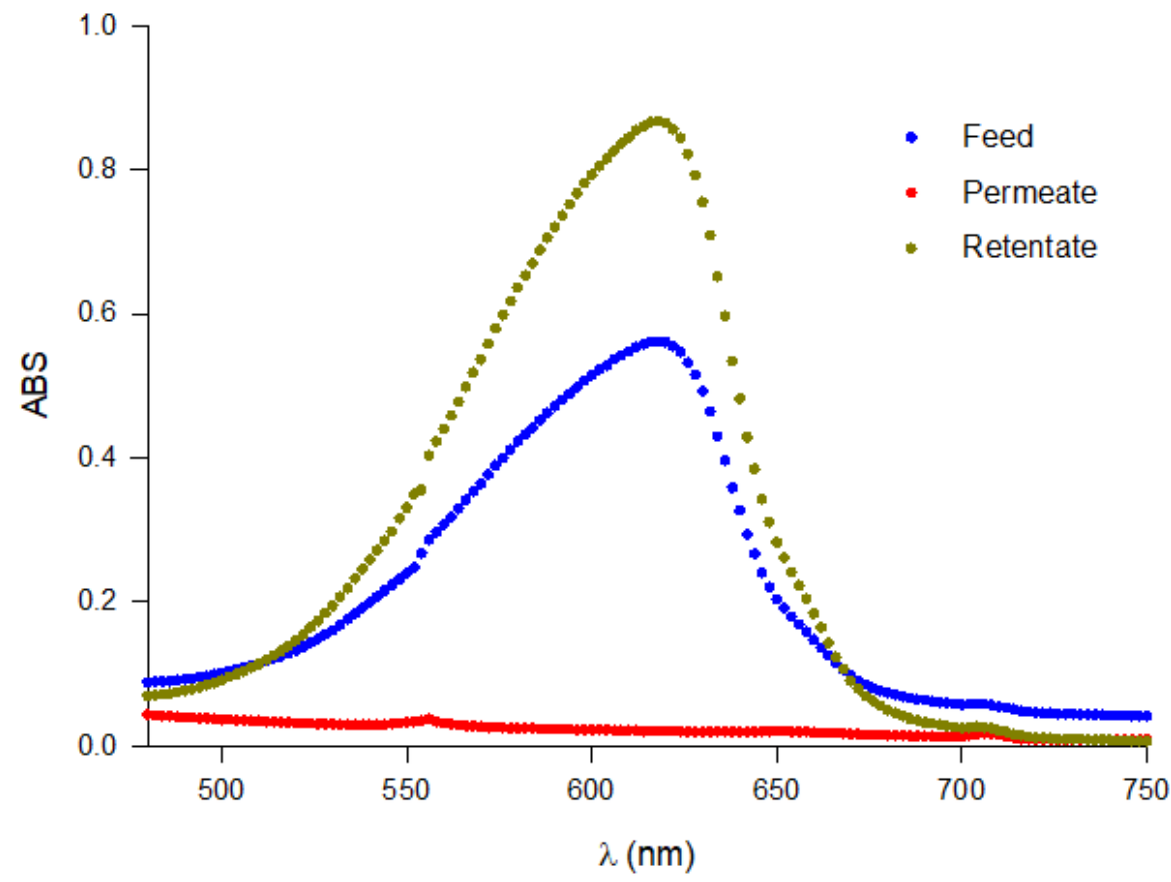

Figure 9. Full scan of the absorbance of UF fractions (feed, retentate and permeate). 
Table 1. Concentration and purity of PC obtained by aqueous extraction followed by UF and diafiltration (PF, purification factor).

\begin{tabular}{cccc}
\hline Samples & $\begin{array}{c}\text { PC Concentration } \\
(\mathbf{m g} / \mathbf{m L})\end{array}$ & PC Purity & PF \\
\hline Feed & $0.232 \pm 0.0042$ & $0.74 \pm 0.030$ & - \\
Permeate & $0.0089 \pm 0.00085$ & - & - \\
Retentate & $1.124 \pm 0.0234$ & $0.93 \pm 0.009$ & 4.84 \\
Final retentate & $1.174 \pm 0.0244$ & $1.16 \pm 0.010$ & 5.06 \\
\hline
\end{tabular}

The concentration of PC in the retentate was4.8-fold higher than that of the feed solution and it was in agreement with the VCF of the process. The rejection of the UF membrane towards the PC was $96.2 \%$ and according to the mass balance of the process, $96.9 \%$ of the PC was recovered in the retentate.

The purity value of the crude extract increased from 0.74 to 0.93 in the UF retentate: accordingly, the UF process allowed a purification factor of 4.84. After six diafiltration cycles, the PC purity of the retentate and the purification factor increased to 1.16 and 5.06, respectively. This behavior can be attributed to the removal of most contaminant particles smaller than the nominal MWCO of the UF membrane $(20 \mathrm{kDa})$ during the first 6 cycles of DF.

\subsection{DNA Analyses}

The agarose gel electrophoresis of two independent extractions is reported in Figure 10. As can be seen, nucleic acid contamination occurred in the feed solution, suggesting that DNA molecules were co-extracted during solubilization with proteins from A. maxima biomass; after ultrafiltration, the DNA molecules were not detected in the retentate, suggesting that the DNA was efficiently removed; on the other hand, DNA was not detected in the permeate fraction, suggesting that during filtration DNA was degraded in very small fragments not detectable through electrophoresis in our conditions. This is corroborated by the evidence of the Abs 260/280 ratio values (Supplementary Table S1).

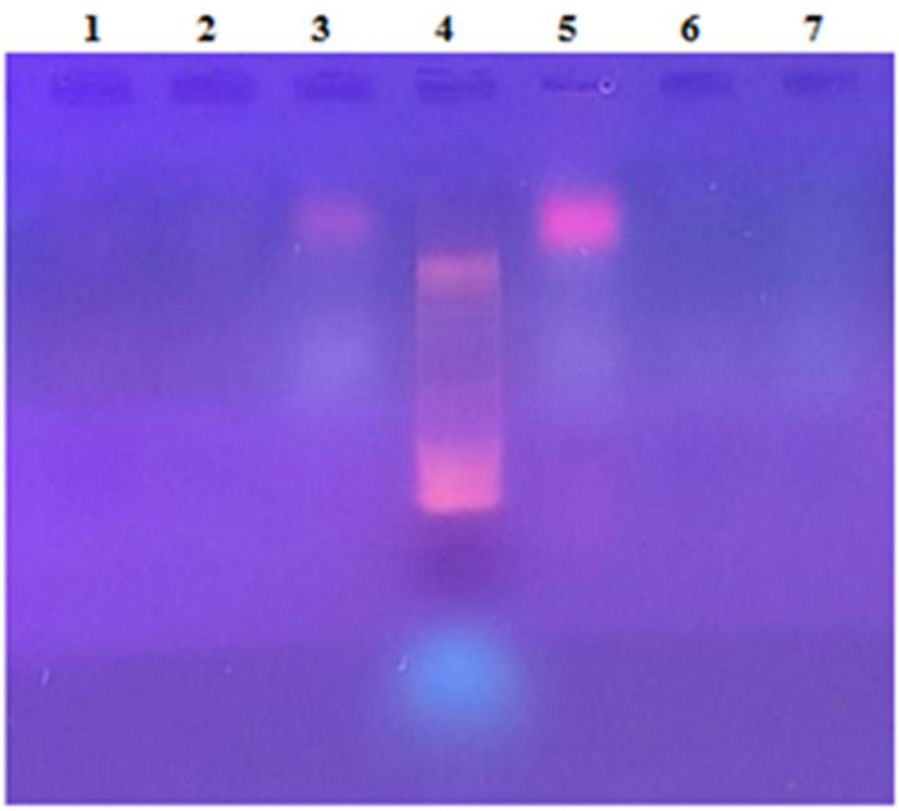

Figure 10. Agarose gel electrophoresis of the UF fractions obtained from the aqueous PC extracts from A. maxima. DNA bands were detected in the feeds (lanes 3 and 5) but not in the retentate fractions (lanes 1 and 6) nor in the permeate fractions (lanes 2 and 7). 10bp DNA ladder was used as electrophoresis markers (Lane 4). 
The contents of DNA measured in all fractions from the UF and diafiltration process of the feed solution are reported in Table 2.

Table 2. Mass balance of DNA in both UF and DF processes.

\begin{tabular}{|c|c|c|c|}
\hline Sample & $\begin{array}{c}\text { DNA } \\
(\mathrm{ng} / \mu \mathrm{L})\end{array}$ & Volume & $\begin{array}{c}\text { DNA } \\
(\mu \mathrm{g})\end{array}$ \\
\hline Feed & $425 \pm 8.5$ & 100 & $42,500.0 \pm 637.5$ \\
\hline UF Permeate & $413 \pm 8.2$ & 80 & $33,040.0 \pm 495.6$ \\
\hline UF Retentate & $473 \pm 9.4$ & 20 & $9460.0 \pm 141.9$ \\
\hline DF1 & $181 \pm 3.6$ & 15 & $2715.0 \pm 40.7$ \\
\hline DF2 & $107 \pm 2.1$ & 15 & $1605.0 \pm 24.1$ \\
\hline DF3 & $52 \pm 1.0$ & 15 & $780.0 \pm 11.7$ \\
\hline DF4 & $25 \pm 0.5$ & 15 & $375.0 \pm 5.6$ \\
\hline DF5 & $20.5 \pm 0.4$ & 15 & $307.5 \pm 4.6$ \\
\hline DF6 & $11 \pm 0.2$ & 15 & $165.0 \pm 2.4$ \\
\hline DF tot & & & $5947.5 \pm 89.2$ \\
\hline Permeate & & & $33,040.0 \pm 495.6$ \\
\hline DFtot + Permeate & & & $38,987.5 \pm 584.8$ \\
\hline
\end{tabular}

According to the mass balance of the process, about $77 \%$ and $14 \%$ of DNA wasrecovered in the permeate and diafiltrate samples, respectively. Therefore, the combination of UF and DF allowed the removal of about $91.7 \%$ of the DNA from the crude extract, thereby improving the purity of the phycocyanin in the retentate fraction.

\section{Discussion}

The extraction protocol developed in this work obtained a very high phycocyanin yield from A. maxima biomass. The biomass-solvent ratio of $0.02 \mathrm{~g} / \mathrm{mL}$ makes possible the use of smaller volumes of extractant in the purification steps and it agrees with data reported by Silveira et al. [29] in the optimization of PC extraction from Spirulina platensis using factorial design. The authors also reported that the use of a biomass-solvent ratio higher than $0.08 \mathrm{~g} / \mathrm{mL}$ produced very concentrated suspensions so that the solvent was unable to promote an appropriate interaction with the biomass for efficient extraction.

It is well known that representative phycobiliproteins in Spirulina are phycocyanin and allophycocyanin $[23,33]$. It is interesting to point out that the allophycocyanin concentration measured in the original crude extract of $A$. maxima was about $0.01 \mathrm{mg} / \mathrm{mL}$, 23-fold less than phycocyanin concentration. This unbalanced content of phycobiliproteins could mainly be attributed to our biological source of $A$. maxima cultivated according to the Oilfox ${ }^{\circledR}$ technology [24].

The electrophoretic profile of $A$. maxima PC crude extract has shown that the majority of the water soluble proteins correspond to the molecular weight of approx. $19 \mathrm{kDa}$; in Spirulina platensis, the pure C-phycocyanin was reported to be formed by two subunits corresponding to $\alpha$ and $\beta$ subunits of 17 and $21 \mathrm{kDa}$, respectively; as the molecular weight of the native purified C-PC was $115 \mathrm{kDa}$, the aggregation state of the purified C-PC was accomplished by the assemblage $(\alpha \beta) 3$ [34]. Despite the literature on the C-phycocyanin extraction and purification from A. maxima [35-37], there is no information, to our knowledge, on the molecular characterization of $\mathrm{C}$-phycocyanin in this species. Under denaturing conditions, our results suggest that the $\mathrm{C}$-phycocyanin in A. maxima could consist of monomers with an apparent molecular weight of approximately $19 \mathrm{kDa}$. Another hypothesis is that, in our conditions, it is not possible to separate the two subunits that therefore appear merged into a single band. Further molecular studies are needed to clarify this finding.

The decrease in permeate flux observed during the UF of the crude extract in selected operating conditions could be attributed to pore blockage and cake formation mechanisms occurring sequentially during the filtration process. A larger drop in the permeate flux followed by long-term decay until reaching a steadystate of about $15 \mathrm{~L} / \mathrm{m}^{2} \mathrm{~h}$ was observed 
by Brião et al. [22] in the UF of a crude PC extract $(0.53 \mathrm{mg} / \mathrm{L})$ by using a PES UF membrane with a MWCO of $60 \mathrm{kDa}$. Higher fluxes (of the order of $50 \mathrm{~L} / \mathrm{m}^{2} \mathrm{~h}$ ) were obtained by Chaiklahan et al. [38] by using membranes of 50 and $70 \mathrm{kDa}$; in this case, the crude extract was previously microfiltered in order to remove cellular fragments before UF.

The UF process has proven effective both in the purification of C-phycocyanin and its five-fold concentration in our experimental conditions regardless of the starting biomasssolvent ratio. Furthermore, UF combined with diafiltration solved the contamination by DNA.

The PC purity and the purification factor measured after the UF/DF treatment of the crude extract are in agreement with data reported by Figueira et al. [21] in the UF of a crude extract of $S$. platensis by using a $50 \mathrm{kDa}$ PES membrane in a flat-sheet configuration. The authors reported a PC recovery between 60 and $99 \%$ and purification factors between 1.35 and 1.57 in different conditions of pressure $\left(1,1.5\right.$ and $\left.2 \mathrm{kgf} / \mathrm{cm}^{2}\right), \mathrm{pH}(6$, 6.5 and 7$)$, temperature $\left(4,14.5\right.$ and $\left.25^{\circ} \mathrm{C}\right)$ and diafiltration cycles $(0,2$ and 4$)$. Similarly, Chaiklahan et al. [38] reported purity ratios of 1.11, 1.03 and 1.08 after the UF of the microfiltered extract with $50 \mathrm{kDa}, 70 \mathrm{kDa}$ and $100 \mathrm{kDa}$ membranes, respectively. The purity ratio of the phycocyanin extract increased approximately 2 -fold when compared to the initial purity (0.54).

On the other hand, Brião et al. [22] reported that the MF and UF membranes did not successfully purify the PC extracted from Spirulina by freeze-thaw extraction. Indeed, the PC purity of the crude extract decreased from 0.355 to 0.345 in the retentate of the MF process (with a flat-sheet polyvinylidene fluoride membrane of $0.4 \mu \mathrm{m}$ as pore diameter) and from 0.403 to 0.382 in the retentate of the UF process (with a flat-sheet PES membrane with a MWCO of $60 \mathrm{kDa}$ ). These results were attributed to the formation of a thick cake layer which blocked the membrane pores, thus preventing the removal of lower molecular weight contaminants from the crude extract. The extraction with sodium phosphate buffer followed by UF (with a tubular PVDF membrane of 30-80 kDa) and one step of diafiltration allowed theenhancement of the purity of the crude extract up to 0.76 , which in any case is lower than the result obtained in our work. In addition, the purification resulted in a 30\% loss of antioxidant activity.

Literature data confirm that the combination of UF with diafiltration allow researchers to obtain C-phycocyanin extracts with purity between 0.75 and 1.5, which are suitable for use as food dye [21,38]. Higher purity ratios (up to $>4$ ) can be reached through the combination of UF with other technologies (i.e., ammonium sulfate precipitation, expandedbed and fixed-bed ion exchange chromatography). Extracts suitable as cosmetic dye (purity of 2.1), biomarkers (purity of 3.0) and for therapeutic and biomedicine applications with an analytical grade (purity $>4.0$ ) were obtained by Figueira et al. [21] according to different combinations of processes, including UF.

After UF, electrophoresis showed that the band of C-phycocyanin is concentrated in the retentate fraction without changes in the molecular weight. Here, we can speculate that the native form of C-phycocyanin in the feed solution had the least dimeric conformation and therefore was retained by the membrane with a $20 \mathrm{kDa}$ cut-off. Structural modifications might occur during C-phycocyanin ultrafiltration [21]; at the temperature of $25^{\circ} \mathrm{C}$, an increase in C-phycocyanin recovery was reported. This increase can be attributed to higher retention due to a slight increase in the molar mass of C-phycocyanin.

\section{Conclusions}

A green and sustainable method for the extraction and purification of phycocyanin (PC) from a strain of Arthrospira maxima has been developed. Aqueous extracts optimized from different biomass-solvent ratios were purified by ultrafiltration (UF) by using a $20 \mathrm{kDa}$ membrane in a flat-sheet configuration. The UF process allowed the recovery of more than $96 \%$ of the PC in the retentate fraction and the removal of about $91.7 \%$ of the DNA content from the crude extract. The purity value of the crude extract increased from 0.74 to 0.93 after the UF process. The application of 6 DF cycles enhanced the purification process, thereby 
obtaining a C-PC extract with a purity degree of 1.16, which is suitable for human food use. The combination of UF with other methodologies (i.e., ammonium sulfate precipitation and ion exchange chromatography) could be a useful approach forenhancing the purity degree of DNA-free ultrafiltered samples, thereby allowing the production of extracts suitable for other uses including therapeutic and biomedicine applications.

Supplementary Materials: The following supporting information can be downloaded at: https:/ / www.mdpi.com/article/10.3390/microorganisms10020308/s1, Figure S1: SDS-PAGE of the pellet after the centrifugation of the extract from $0.005 \mathrm{~g} / \mathrm{mL}$ (lanes 1), $0.010 \mathrm{~g} / \mathrm{mL}$ (lanes 2), $0.015 \mathrm{~g} / \mathrm{mL}$ (lane 4) and $0.020 \mathrm{~g} / \mathrm{mL}$ (lane 5) biomass-solvent ratio. $20 \mu \mathrm{L}$ of each extract wasloaded on the gel. Precision Plus ProteinTM Standards (Biorad, Hercules, CA, USA) was loaded on the lane 3; Table S1: Values of DNA absorbance at 260 and $280 \mathrm{~nm}$ in the aqueous PC solution (feed), UF and DF fractions and the respective absorbance ratios.

Author Contributions: Conceptualization, S.M. and A.C.; methodology, D.M.N., A.P., D.O., V.O., R.M. and C.C.; formal analysis, A.P., D.M.N. and C.C.; investigation, A.F.; resources, F.A.F.; data curation, S.M., A.P. and A.C.; writing-original draft preparation, D.M.N., S.M. and A.C.; writingreview and editing, S.M. and A.C.; supervision, S.M., A.F. and A.C. All authors have read and agreed to the published version of the manuscript.

Funding: This research was carried out with the financial support of the University of Calabria (ex $60 \%$ research found 2020-2021).

Institutional Review Board Statement: Not applicable.

Informed Consent Statement: Not applicable.

Data Availability Statement: Not applicable.

Conflicts of Interest: The authors declare no conflict of interest.

\section{References}

1. Buono, S.; Langellotti, A.L.; Martello, A.; Rinna, F.; Fogliano, V. Functional ingredients from microalgae. Food Funct. 2014, 5, 669-1685. [CrossRef] [PubMed]

2. Matos, J.; Cardoso, C.; Bandarra, N.M.; Afonso, C. Microalgae as a healthy ingredient for functional food: A review. Food Funct. 2017, 8, 2672-2685. [CrossRef] [PubMed]

3. Soto-Sierra, L.; Stoykova, P.; Nikolov, Z.L. Extraction and fractionation of microalgae-based protein products. Algal Res. 2018, 36, 175-192. [CrossRef]

4. Grosshagauer, S.; Kraemer, K.; Somoza, V. The true value of Spirulina. J. Agric. Food Chem. 2020, 68, 4109-4115. [CrossRef]

5. Moraes, C.C.; Kalil, S.J. Strategy for a protein purification design using C-phycocyanin extract. Bioresour. Technol. 2009, 100, 5312-5317. [CrossRef]

6. Reddy, M.C.; Subliashini, J.; Mahipal, S.V.K.; Bhat, V.B.; Reddy, P.S.; Kiranmai, G.; Madyastha, K.M.; Reddanna, P. C-Phycocyanin, a selective cyclooxygenase-2 inhibitor, induces apoptosis in lipopolysaccharide-stimulated RAW 264.7 macrophages. Biochem. Biophys. Res. Commun. 2003, 304, 385-392. [CrossRef]

7. Eriksen, N.T. Production of phycocyanin-A pigment with applications in biology, biotechnology, foods and medicine. Appl. Microbiol. Biotechnol. 2008, 80, 1-14. [CrossRef]

8. Gantar, M.; Simovic, D.; Djilas, S.; Gonzales, W.W.; Miksovska, J. Isolation, characterization and antioxidative activity of C-phycocyanin from Limnothrix sp. strain 37-2-1. J. Biotechnol. 2012, 159, 21-26. [CrossRef]

9. Raposo, M.F.L.; Morais, R.M.S.C.; Morais, A.M.M.B. Health applications of bioactive compounds from marine microalgae. Life Sci. 2013, 93, 479-486. [CrossRef]

10. Spolaore, P.; Joannis-Cassan, C.; Duran, E.; Isambert, A. Review commercial applications of microalgae. J. Biosci. Bioeng. 2006, 101, 87-201. [CrossRef]

11. Antelo, F.S.; Costa, J.A.V.; Kalil, S.J. Purification of C-phycocyanin from Spirulina platensis in aqueoustwo-phase systemsusing an experimental design. Braz. Arch. Biol. Technol. 2015, 58, 1-11. [CrossRef]

12. Benedetti, S.; Rinalducci, S.; Benvenuti, F.; Francogli, S.; Pagliarani, S.; Giorgi, L.; Micheloni, M.; D'Amici, G.M.; Zolla, L.; Canestrari, F. Purification and characterization of phycocyanin from the blue-green alga Aphanizomenonflos-aquae. J. Chromatogr. $B$ 2006, 833, 12-18. [CrossRef] [PubMed]

13. Kamble, S.P.; Gaikar, R.B.; Padalia, R.B.; Shinde, K.D. Extraction and purification of C-phycocyanin from dry Spirulina powder and evaluating itsantioxidant, anticoagulation and prevention of DNA damage activity. J. Appl. Pharm. Sci. 2013, 3, 149-153.

14. Kumar, D.; Dhar, D.W.; Pabbi, S.; Kumar, N.; Walia, S. Extraction and purification of C-phycocyanin from Spirulina platensis (CCC540). Indian J. Plant Physiol. 2014, 19, 184-188. [CrossRef] [PubMed] 
15. Rito-Palomares, M.; Nuñez, L.; Amador, D. Practical application of aqueous two-phase systems for the development of a prototype process for phycocyanin recovery from Spirulina maxima. J. Chem. Technol. Biotechnol. 2001, 76, 1273-1280. [CrossRef]

16. Sørensen, L.; Hantke, A.; Eriksen, N.T. Purification of the photosynthetic pigment C-phycocyanin from heterotrophic Galdieriasulphuraria. J. Sci. Food Agric. 2013, 93, 2933-2938. [CrossRef] [PubMed]

17. Li, J.; Chase, H.A. Applications of membrane technique for purification of natural products. Biotechnol. Lett. 2010, 32, 601-608. [CrossRef]

18. Conidi, C.; Drioli, E.; Cassano, A. Membrane-based agro-food production processes for polyphenol separation, purification and concentration. Curr. Opin. Food Sci. 2018, 23, 149-164. [CrossRef]

19. Herrera, A.; Boussiba, S.; Napoleone, V.; Hohlberg, A. Recovery of c-phycocyanin from the cyanobacterium Spirulina maxima. J. Appl. Phycol. 1989, 1, 325-331. [CrossRef]

20. Jaouen, P.; Lépine, B.; Rossignol, N.; Royer, R.; Quéméneur, F. Clarification and concentration with membrance technology of a phycocyanin solution extracted from Spirulina platensis. Biotechnol. Techol. 1999, 13, 877-881. [CrossRef]

21. Figueira, F.D.; Moraes, C.C.; Kalil, S.J. C-phycocyanin purification: Multiple processes for different applications. Braz. J. Chem. Eng. 2018, 35, 1117-1128. [CrossRef]

22. Brião, V.B.; Sbeghen, A.L.; Colla, L.M.; Castoldi, V.; Seguenka, B.; Schimidt, G.D.; Costa, J.A.V. Is downstream ultrafiltration enough for production of food-grade phycocyanin from Arthrospira platensis? J. Appl. Phycol. 2020, 32, 1129-1140. [CrossRef]

23. Balti, R.; Zayoud, N.; Hubert, F.; Beaulieu, L.; Massé, A. Fractionation of Arthrospira platensis (Spirulina) water soluble proteins by membrane diafiltration. Sep. Purif. Technol. 2021, 256, 117756. [CrossRef]

24. Oil Fox SA. Instalacion para el Cultivo Extensivo e Intensivo de Microalgas en Invernaderos de Estructura Tubular tipo Carrusel. Patent AR070504B1, 19 February 2016.

25. Mittal, R.; Lamdande, A.G.; Sharma, R.; Raghavarao, K.S.M.S. Membrane processing for purification of R-phycoerythrin from marine macro-alga, Gelidiumpusillum and process integration. Sep. Purif. Technol. 2020, 252, 117470. [CrossRef]

26. Bennett, A.; Bogorad, L. Complementary chromatic adaptation in a filamentous blue green alga. J. Cell Biol. 1973, 58, 419-435. [CrossRef]

27. Patel, A.; Mishra, S.; Pawar, R.; Ghosh, P.K. Purification and characterization of C-Phycocyanin from cyanobacterial species of marine and freshwater habitat. Protein Expr. Purif. 2005, 40, 248-255. [CrossRef]

28. Abalde, J.; Bentancourt, L.; Torres, E.; Cid, A.; Barwell, C. Purification and characterization of phycocyanin from the marine cyanobacterium Synechococcus sp. IO9201. Plant Sci. 1998, 136, 109-120. [CrossRef]

29. Silveira, S.T.; Burkert, J.F.M.; Costa, J.A.V.; Burkert, C.A.V.; Kalil, S.J. Optimization of phycocyanin extraction from Spirulina platensis using factorial design. Bioresour. Technol. 2007, 98, 1629-1634. [CrossRef] [PubMed]

30. Bradford, M.M. Rapid and sensitive method for the quantitation of microgram quantities of protein utilizing the principle of protein-dye binding. Anal. Biochem. 1976, 72, 248-254. [CrossRef]

31. Laemli, U.K. Cleavage of structural proteins during the assembly of the head of bacteriophage T4. Nature 1970, 227, 680-685. [CrossRef]

32. Reis, A.; Mendes, A.; Lobo-Fernandes, H.; Empis, J.A.; Novais, J.M. Production, extraction and purification of phycobiliproteins from Nostoc sp. Bioresour. Technol. 1998, 66, 181-187. [CrossRef]

33. Fernández-Rojas, B.; Hernández-Juárez, J.; Pedraza-Chaverri, J. Nutraceutical properties of phycocyanin. J. Funct. Foods 2014, 11, 375-392. [CrossRef]

34. Song, W.; Zhao, C.; Wang, S. A large-scale preparation method of high purity C-phycocyanin. Int. J. Biosci. Biochem. Bioinform. 2013, 3, 293-297.

35. Ruiz-Domínguez, M.C.; Jáuregui, M.; Medina, E.; Jaime, C.; Cerezal, P. Rapid green extractions of C-phycocyanin from Arthrospira maxima for functional applications. Appl. Sci. 2019, 9, 1987. [CrossRef]

36. Antonio-Marcos, E.; Hernández-Vázquez, L.; Olguín, E.J.; Monroy, O.; Navarro-Ocaña, A. C-phycocyanin from Arthrospira maxima LJGR1: Production, extraction and protection. J. Adv. Biotechnol. 2016, 5, 659-666. [CrossRef]

37. Rodríguez-Sánchez, R.; Ortiz-Butrón, R.; Blas-Valdivia, V.; Hernández-García, A.; Cano-Europa, E. Phycobiliproteins or Cphycocyanin of Arthrospira (Spirulina) maxima protect against $\mathrm{HgCl}_{2}$-caused oxidative stress and renal damage. Food Chem. 2012, 135, 2359-2365. [CrossRef]

38. Chaiklahan, R.; Chirasuwan, N.; Loha, V.; Tia, S.; Bunnag, B. Separation and purification of phycocyanin from Spirulina sp. using a membrane process. Bioresour. Technol. 2011, 102, 7159-7164. [CrossRef] 